\title{
Effect of different dryers and drying conditions on acceptability and physico-chemical characteristics of durian leather
}

\begin{abstract}
Optimization study on drying condition of durian leather was carried out using Response Surface Methodology (RSM). The optimization was conducted for two different dryers, oven dryer and forced-air cabinet dryer, with temperature and time of drying as independent variables. It was shown that both variables significantly affected most of the sensory properties. For both dryers, the optimum points for 5 sensory attributes evaluated including taste, aroma, texture, appearance and overall acceptability, were at temperatures ranged from 47-55C for 10-14 h. Based on the overall acceptability, the optimum condition for ovendried leather was achieved at temperature $50 \mathrm{C}$ for $12.6 \mathrm{~h}$, while for cabinet-dried leather at $52.5 \mathrm{C}$ for $10 \mathrm{~h}$. Results showed that panelist preferred product dried with low temperature-long time compared with high temperature-short time. Except for Hunter color b value of cabinet-dried product, results also indicated that drying condition was significantly influencing the physicochemical properties such as moisture, Aw, nonenzymatic browning, texture, vitamin $\mathrm{C}$ and color of durian leather.
\end{abstract}

Keyword: Dryers; Optimization; Durian leather; Drying conditions 